\title{
CORRESPONDENCE
}

\section{Long-term follow-up of thoracoscopic talc pleurodesis for primary spontaneous pneumothorax}

\section{To the Editors:}

I read with interest the study by GYöRIK et al. [1] of talc pleurodesis for primary spontaneous pneumothorax. The results were not surprising as they confirm previous studies. What was surprising, however, was the lack of a control group, the lack of an intention-to-treat analysis and the failure of the paper's discussion to mention these absences as a weakness.

The authors report a 95\% long-term success rate for talc pleurodesis, which represents 53 out of 56 patients initially treated successfully with the technique. There were, however, 112 patients who underwent the procedure. The authors were only able to contact 63 of them; the remaining 49 apparently were not contactable because of "geographical movement."

I am troubled that an intention-to-treat analysis is not reported. Given the 53 long-term successes and 112 original treatments, I arrive at a success rate of $47 \%$, which is half of what the authors report. Together with the lack of a control group of patients who suffered spontaneous pneumothoraces but did not undergo talc pleurodesis, I find it unclear as to what can be reliably concluded from this study.

\section{Oransky}

Division of General Internal Medicine, Dept of Internal Medicine, New York University School of Medicine, New York, NY, USA.

\section{STATEMENT OF INTEREST}

None declared.

\section{REFERENCES}

1 Györik S, Erni S, Studler U, Hodek-Wuerz R, Tamm M, Chhajed PN. Long-term follow-up of thoracoscopic talc pleurodesis for primary spontaneous pneumothorax. Eur Respir J 2007; 29: 757-760.

DOI: $10.1183 / 09031936.00044107$

\section{From the authors:}

We agree with I. Oransky that it is always a considerable weakness to be unable to follow up all patients. We believe that the outcome of our study [1] was not affected in a major way by the missing patients, as spontaneous pneumothorax is not a chronic disease or a malignant condition. We also believe that the geographical movement in this young population is unlikely to bias the follow-up of lung function. However, we agree with I. Oransky that effort should be directed towards good patient follow-up.

\section{P.N. Chhajed and M. Tamm}

Pulmonary Medicine, University Hospital Basel, Basel, Switzerland.

\section{STATEMENT OF INTEREST}

None declared.

\section{REFERENCES}

1 Györik S, Erni S, Studler U, Hodek-Wuerz R, Tamm M, Chhajed PN. Long-term follow-up of thoracoscopic talc pleurodesis for primary spontaneous pneumothorax. Eur Respir J 2007; 29: 757-760.

DOI: $10.1183 / 09031936.00059207$

\section{To the Editors:}

We read with great interest the recent article by GYÖRIK et al. [1], which presented their long-term experience of primary spontaneous pneumothoraces (PSPs) treated by spontaneous breathing thoracoscopy and talc pleurodesis, and would like to invoke a more conscious use of talc pleurodesis.

Talc represents the most reliable sclerosing agent for pleurodesis currently available in the clinical setting. However, we question the practice to treat all PSPs with persisting air leak of $>48$ h or simple recurrences with talc pleurodesis. To us, this proceeding seems a little bit like breaking a butterfly upon a wheel.

PSPs occur typically in young, thin and tall males and females aged $<30$ yrs [2]. Many of these are smokers, predisposing this group for developing lung cancer with a probability of $7.7 \%$ and $5.7 \%$ in males and females, respectively [3]. In our opinion, a wide use of talc pleurodesis in this young patient group unjustifiably increases the complexity and morbidity of potential later operations for lung cancer in the future. Additionally, talc has been shown to disseminate into neighbouring organs, such as pericardium, mediastinum, contralateral lung and liver [4, 5], inducing potentially carcinogenic granuloma tissue. We hypothesise that the authors applied talc in their patients to compensate for the high number of missed blebs and bullae that were not treatable during spontaneous breathing thoracoscopy, resulting in a formidably low recurrence rate of only 5\%. The authors' findings have to be compared with video-assisted thoracoscopy, 